\title{
BMJ Open Emotional reactions in parents of the youth who experienced the Utøya shooting on 22 July 2011; results from a cohort study
}

\author{
Tonje Holt, ${ }^{1,2}$ Tine Jensen, ${ }^{2,3}$ Grete Dyb, ${ }^{3,4}$ Tore Wentzel-Larsen ${ }^{3,5}$
}

To cite: Holt T, Jensen T, Dyb G, et al. Emotional reactions in parents of the youth who experienced the Utøya shooting on 22 July 2011; results from a cohort study. BMJ Open 2017;7:e015345. doi:10.1136/ bmjopen-2016-015345

- Prepublication history and additional material for this paper are available online. To view these files, please visit the journal online (http://dx.doi. org/10.1136/bmjopen-2016015345).

Received 28 November 2016 Revised 14 August 2017 Accepted 24 August 2017

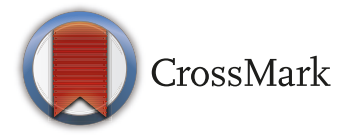

${ }^{1}$ Mental \& Physical health, Norwegian Institute of Public Health and Norwegian Centre for Violence and Traumatic Stress Studies, Oslo, Norway

${ }^{2}$ Department of Psychology, University of Oslo, Oslo, Norway ${ }^{3}$ Norwegian Centre for Violence and Traumatic Stress Studies, Oslo, Norway

${ }^{4}$ Faculty of medicine, University of Oslo, Oslo, Norway

${ }^{5}$ Center for Child and Adolescent Mental Health, Eastern and Southern Norway, Oslo, Norway

Correspondence to

Dr Tonje Holt; tonje.holt@fhi.no

\section{ABSTRACT}

Objective and setting The objective of this study was to provide knowledge about the emotional reactions in parents whose offspring experienced a mass shooting on Utøya island in Norway in 2011. The research questions included whether parents' reactions were influenced by their offspring's symptom level, age, living situation and parental gender.

Design The study was designed as an open cohort study. The data were collected at two time points; 4-5 months and 14-15 months after the shooting.

Participants The participants were 531 parents of youth exposed to the Utøya island attack.

Outcome measures The Parental Emotional Reaction Questionnaire measured parents' reactions, and University of California, Los Angeles Post-traumatic Stress Disorder Reaction Index measured youths' post-traumatic stress symptoms.

Results Parental emotional reactions were positively related to post-traumatic stress reactions in offspring at wave 1: Est. $=0.20,95 \% \mathrm{Cl} 0.10$ to $0.30, p<0.001$, over time (wave 1and wave 2 nested within individuals): Est. $=0.23, \mathrm{Cl} 0.13$ to $0.32, \mathrm{p}<0.001$, and at wave 2 : Est. $=0.26$, Cl 0.12 to $0.39, p<0.001$. Youths' age was not significantly related to parental emotional reactions, neither at wave 1: Est. $=0.19, \mathrm{Cl}-0.40$ to $0.77, \mathrm{p}=0.531$, over time: Est. $=0.26, \mathrm{Cl}-0.27$ to $0.79, \mathrm{p}=328$, nor at wave 2: Est. $=0.32, \mathrm{Cl}-0.41$ to $1.05, \mathrm{p}=0.389$. Mothers were more emotionally upset than fathers both at wave 1: Est. $=-5.66, \mathrm{Cl}-7.63$ to $-3.69, \mathrm{p}<0.001$, over time: Est. $=-5.36, \mathrm{Cl}-7.18$ to $-3.55, \mathrm{p}<0.001$, and at wave 2: Est. $=-5.33, \mathrm{Cl}-7.72$ to $-2.53, \mathrm{p}<0.001$.

Conclusions The findings suggest that parenting after trauma should be addressed in outreach programmes and in planning of healthcare services.

\section{INTRODUCTION}

Parents often face their own challenges when their children experience potentially traumatic events such as accidents, life-threatening illness, sudden death of a close family member, violence or sexual abuse. Most of the studies investigating the parental burden of having a traumatised child have focused on parental post-traumatic stress symptoms
Strengths and limitations of this study

- The study is one of the few studies highlighting parental emotional reactions in the aftermath of a traumatising event.

- The study is based on a large sample of caregivers whose children experienced a terrorist shooting.

- Face-to-face interviews were conducted with the majority of the parents.

- The data are collected at two time points. However, there are some missing data on wave 2 .

(PTSS) ${ }^{1-6}$ and other mental health problems such as depression and anxiety. ${ }^{7-9}$ Results from all these studies show that parents are at high risk of developing PTSS and other mental health symptoms when their child is exposed to a traumatic event. However, while this is important, parents might have other emotional reactions and worries that encompass a broader spectrum of emotional responses than mental health symptoms, such as feeling upset, distressed and sad because of what happened or feeling guilty because they were not able to prevent bad things from happening to their child. Parents may also experience anger towards a perpetrator or towards the authorities for not punishing a perpetrator sufficiently. Others may worry excessively that something terrifying could happen again, and they may feel uncertainty about how their offspring will cope in the future. All these reactions may influence parents' own psychological well-being, alter their parenting practices, and interfere with their ability to be emotionally present and supportive of their children. ${ }^{10-13}$

Only a few studies have investigated parents' broad emotional reactions to their children's potentially traumatic experiences. ${ }^{1415}$ Parental responses may vary according to the type of trauma their child has experienced. ${ }^{16}$ After illness or injury parents may experience 
shock ${ }^{17}$ or distress. ${ }^{18}$ For instance, in one study Foster $e t$ $a l^{17}$ interviewed 40 parents of critically injured children. They found that parents felt an initial shock about the injury regardless of how the injury occurred. After child sexual abuse it has been shown that parents' reactions are related to their child's mental health symptoms. ${ }^{19}$ Furthermore, studies show that parental distress and guilt are related to parents' mental health symptoms, ${ }^{20}$ and that their reactions may be modified as their child engages in therapy. ${ }^{141521}$ Despite this knowledge, little is known about what influences parental emotional reactions.

Guided by developmental models depicting the importance of the relationship between parents and offspring after their child has experienced potentially traumatic events, ${ }^{22}$ one starting point for learning more about parents' emotional reactions is to examine the extent to which their emotions are influenced by the problems expressed by their offspring. Parents' reactions tap into the core essence of what parenting is. The primary role of a parent is to provide protection and serve as their child's 'protective shield'. ${ }^{22}$ When something terrifying happens to their child, parents may feel that they have failed in their primary role as protectors, and thus develop feelings of guilt, inadequacy and distress. In addition, when their offspring are struggling with problems such as nightmares, difficulty concentrating and withdrawal from activities in the aftermath of the terrifying event, it is likely that parents experience even greater guilt, inadequacy, concern, sadness and distress. In the current study, we therefore wanted to investigate the association between the symptoms expressed by the youth, and the emotional reactions expressed by the parents.

A second way to understand parents' reactions better is to investigate the relationship between parental emotions and the age and living situation of their offspring. In particular, there is a need to investigate the reactions in parents whose children are above the age of 18 years, as few studies have addressed this subject. From a developmental perspective, it is reasonable to assume that parents would be more emotionally involved in their offspring's lives while their offspring are young and still under parental protection and guidance. Parents may feel that their parenting responsibilities diminish, as their offspring grow older and become independent. Further, it is reasonable to assume that parents' feelings of responsibility for their child's development are strongest when the offspring are young because these offspring may be seen as more vulnerable and less able to cope, and are more often living at home. When the child lives at home, the parent may also have more direct knowledge of the child's struggles. Thus, we wanted to investigate whether parents of young offspring living at home were more likely to report higher levels of emotional reactions.

A third way to increase our understanding of parents' emotional reactions is to investigate possible differences between the reactions of mothers and fathers. Many studies have found that women are more likely to express higher levels of post-trauma reactions than men. ${ }^{24}{ }^{25}$
However, it is not clear whether this gender difference is also found between parents of different gender. Studies of parents to children who suffer from serious illnesses or injuries show mixed results. ${ }^{5}$ While some studies find that mothers are more likely to develop PTSS, ${ }^{2627}$ other studies do not find such differences. ${ }^{28}{ }^{29}$ It could also be that since mothers have traditionally had the primary responsibility for raising children and caring for the family, at least in Western societies, ${ }^{30}{ }^{31}$ they also feel a greater responsibility for helping their children cope, and thus, are more affected by their suffering than fathers are. However, these traditional values have changed in many societies during the last decades, and fathers now have a more equal role in child-rearing and family participation, ${ }^{32}$ so it may be that there would be no gender differences in emotional reactions. Furthermore, the Utøya terrorist attack was such a horrific event that one could expect that it would cause high emotional distress regardless of whether the caregiver was a mother or a father. Thus, we wanted to investigate whether there were gender differences in levels of parental emotional reactions.

In this study, the goal was to understand more of parental emotional reactions and to investigate what influenced these reactions by asking parents of youth and adults exposed to the terrorist attack on Utøya island in Norway, 22 July 2011 about their emotional reactions at two time points after the attack. A better understanding of what may influence parents' reactions could help us to evaluate their needs and provide tailored interventions for parents whose children have experienced traumatic events. We investigated the following research questions:

A. What was the relationship between the youth's PTS-level and parental emotional reactions, during follow-up after the shooting?

B. To what extent were the youth's age and living situation associated with the level of parental emotional reactions, during follow-up after the shooting?

C. Was there any difference in the level of emotional reactions of mothers and fathers, during follow-up after the shooting?

\section{METHOD}

\section{Procedure}

All participants were parents of youth and adults exposed to the terrorist attack on Utøya island, 22 July 2011. On that day, politically active youth from all over the country were gathered at Utøya to participate in a summer camp when a terrorist dressed as a police officer arrived on the island. The terrorist shot innocent youth for over 1 hour. The massacre left $69 \mathrm{dead}$, and many were injured. During that time, most of the parents were exposed to shocking images on television not knowing whether their offspring were still alive or not, and many talked to their offspring on the phone but were unable to provide help.

The data used in this article were collected in two waves. The first wave of data collection took place 4-5 months following the terrorist attack, whereas the second took 
place 15-15 months after the attack. All parents of survivors between 13 years and 32 years were invited to participate by mail and were subsequently contacted by phone. Parents of survivors older than 32 years $(n=8)$ were excluded because they were much older parents of survivors working at the camp. Parents of children younger than 13 years $(n=4)$ were excluded because all these were parents of children working at the camp. For further description of the recruitment procedure, see Dyb, Jensen and Nygaard et al, and Stene and Dyb. ${ }^{33} 34$

All parents answered a paper-and-pencil questionnaire. With a few exceptions, the parents of the older survivors ( $\geq 19$ years) answered a questionnaire mailed to their homes, whereas the parents of the youngest survivors $(\leq 18$ years) filled in the Parental Emotional Reaction Questionnaire (PERQ) after being interviewed face-to face in structured self-report interviews. The same measurements were applied in both data collection procedures. A total of 309 parents $(68.2 \%)$ at wave 1 and $283(66.4 \%)$ at wave 2 , participated in face-to-face interviews. The rest $(31.8 \%$ at wave 1 and $33.6 \%$ at wave 2) answered a paper-andpencil questionnaire. The parental and youth interviews were conducted independent of each other. The youth were not present when their parents were interviewed and vice versa, and study participation by one informant was not dependent of the other. All interviewers were health personnel, specifically trained for the current study. All participants provided a written, active consent to participate.

\section{Participants}

The sample consisted of 531 parents participating at one or two time points. Most of them were women (299, $56.3 \%)$, and the mean age was 48.2 years $(S D=6.4)$ at the time of the terrorist attack. At wave 1, 453 parents participated, at wave 2, 426 parents participated and 348 parents (65.5\% of all participating parents) participated at both waves. At the first wave most of the parents $(n=430,94.9 \%)$ were biological parents, 16 (3.5\%) were step-parents and $7(1.5 \%)$ were others. At the second wave, $409(96.0 \%)$ of the participating parents were biological parents, 13 $(3.1 \%)$ were step-parents and $4(0.9 \%)$ were others. See table 1 for a short description of the sample.

Of all the survivors between 13 years and 32 years of age $(n=482), 330$ survivors $(68.5 \%)$ are represented by at least one participating caregiver at wave land/or wave 2. There were no significant differences between participating survivors and non-participating survivors regarding their age and gender. For a further description of the participants (parents and survivors), see Dyb, Jensen and Nygaard et al, and Stene and Dyb. ${ }^{33} 34$

\section{Measurements}

Parent emotional reaction questionnaire

PERQ is a self-report questionnaire in which the parents are asked to rate their feelings on a 5-point Likert Scale ranging from 1 to 5 (1=never, 5 =always), indicating how often they experienced each emotional reaction during the last 2 weeks.
Table 1 Participant characteristics and composite scores for youth PTSD and parental emotional reactions at two waves $(n=531)$

\begin{tabular}{|c|c|}
\hline Variable & n (\%) \\
\hline \multicolumn{2}{|l|}{ Female/male caregiver } \\
\hline $\begin{array}{l}\text { Mother/stepmother/other female } \\
\text { caregiver }\end{array}$ & $299(56.3)$ \\
\hline Father/stepfather/othermale caregiver & $232(43.7)$ \\
\hline \multicolumn{2}{|l|}{ Parental age, 22 July 2011} \\
\hline Range & 28-73 \\
\hline Mean & $48.2(S D=6.4)$ \\
\hline \multicolumn{2}{|l|}{ Parental education* (6 missing) } \\
\hline Higher education & 309 (58.9) \\
\hline Lower education & $216(41.1)$ \\
\hline \multicolumn{2}{|l|}{ Youth's living situation, wave 1 (73 missing) } \\
\hline Living with one or two parents & $304(66.4)$ \\
\hline Not living with one or two parents & $154(33.6)$ \\
\hline \multicolumn{2}{|c|}{$\begin{array}{l}\text { Change in living situation from wave } 1 \text { to wave } 2 \text { (177 } \\
\text { missing) }\end{array}$} \\
\hline No change, living at home & $172(48.6)$ \\
\hline Moving out & $55(15.5)$ \\
\hline No change, living away from home & $116(32.3)$ \\
\hline Moving home & $11(3.1)$ \\
\hline \multicolumn{2}{|l|}{ Youth's gender } \\
\hline Girls & $258(48.6 \%)$ \\
\hline Boys & $273(51.4 \%)$ \\
\hline \multicolumn{2}{|l|}{ Youth's age, 22 July 2011} \\
\hline Range & 13.3-29.6 \\
\hline Mean & $16.68(S D=2.74)$ \\
\hline \multicolumn{2}{|l|}{ Youth's sum PTSD scores wave 1} \\
\hline Range & $2-52$ \\
\hline Mean & $26.22(S D=11.65)$ \\
\hline \multicolumn{2}{|l|}{ Youth's sum PTSD scores wave 2} \\
\hline Range & $6-16$ \\
\hline Mean & $20.35(S D=11.46)$ \\
\hline \multicolumn{2}{|l|}{ Parental sum PERQ scores wave $1(n=424)$} \\
\hline Range & $18-90$ \\
\hline Mean & $40.42(S D=10.92)$ \\
\hline \multicolumn{2}{|l|}{ Parental sum PERQ scores wave $2(n=401)$} \\
\hline Range & $18-74$ \\
\hline Mean & $34.83(\mathrm{SD}=11.73)$ \\
\hline
\end{tabular}

*Information about parental education is gathered from the wave 1 reporting.

PERQ, Parental Emotional Reaction Questionnaire; PTSD, posttraumatic stress disorder.

Higher scores represent higher levels of emotional reactions. The original instrument consisted of 15 items and was developed to capture parents' emotional reactions to their child experiencing sexual abuse. ${ }^{19}$ The internal consistency 
of this scale has previously been calculated to be $\alpha=0.87$, and the test-retest reliability has previously been calculated to be $r=0.90{ }^{19}$ The 15 -item instrument was later expanded to a generic version that also captured reactions related to all traumatic events. The items are shown in (online supplementary electronic appendix 1). The generic English version of PERQ was translated and back-translated into Norwegian in cooperation with the developers. However, some items were slightly altered and some were added. This modification was conducted to meet the purposes of this particular study, and some of the alterations were selected from suggestions based on an evaluation of the scale. ${ }^{35}$ In addition, one item was omitted because it was not applicable to this study. After these modifications, the scale consisted of 18 items. In the current sample, the internal consistency of the 18-item scale was $\alpha=0.90$ at wave 1 and $\alpha=0.93$ at wave 2 . The composite sum scores based on the 18 PERQ items are shown in table 1.

University of California, Los Angeles post-traumatic stress disorder reaction index (UCLA PTSD-RI)

The UCLA PTSD-RI ${ }^{36}$ is a questionnaire measuring the youth's PTSS according to the fourth Diagnostic and Statistical Manual of Mental Disorders (DSM-IV). ${ }^{37}$ The scale constitutes 20 items for which responses are recorded on a 5-point scale, ranging from 0 ('never') to 4 ('most of the time') with respect to how frequently the youth had experienced the symptoms over the past month. Seventeen of the items constituted the total score (range: $0-68$ ), where higher scores represent higher symptom severity. Three of the items have two alternative formulations, but only the highest score is used to calculate the total score of the scale. Therefore, 17 items make up the total symptom scale score, corresponding to 4th Diagnostic and Statistical Manual of Mental Disorders (DSM-IV) criteria for PTSD constituting the re-experiencing, the avoidance and the arousal subscales. Cronbach's $\alpha$ for PTSD-RI was $\alpha=0.92$ at wave 1 .

The composite scores of youth PTSD scores are shown in table 1.

The data set had missing values $\leq 5 \%$. The single missing items were handled by computing values based on the scores of the remaining items if missing values within sum scores of PERQ and UCLA were $\leq 20 \%$.

\section{Statistical analyses}

We performed mixed effects analyses to investigate the relationships of characteristics of the child (age, living situation and symptom level) and parental gender with the level of parental emotional reactions at two waves. Mixed effects models account for the nested nature of the data. In addition, the models have the advantage of estimating measures of random variation both between and within participants. ${ }^{38}$ Given the design of the current study, the data set was nested by families in that many of the youth were represented by more than one participating parent and in some analyses there were repeated measures (waves 1 and 2) within individuals. Specifically, to account for the dependency of these observations, caregivers were nested in family units in all models, and in two of the models, waves (wave 1 and wave 2) were nested within parents (three-level models).

Four models were investigated. Models 1 and 4 were two-level models, and models 2 and 3 were three-level models. In the first model, the level of parental emotional reactions at wave 1 was set up as the dependent variable, in the second and third model, parental emotional reactions over time (wave 1 and wave 2 nested within caregivers) constituted the dependent variable, and in the fourth model, parental emotional reaction at wave 2 was the dependent variable. In the first, second and third model, youth's symptom scores from wave 1, youth's age, living situation and parental gender were entered as explanatory variables. In the fourth model the same variables were entered but the youth's symptom scores from wave 1 were replaced with the youth's symptom scores from wave 2 and the youth's living situation was replaced with change in child's living situation from wave 1 to wave 2. Interactions with time were included in the third model for the following variables: youth's PTSS, youth's age and living situation and parental gender. To sum up, model 1 was a two-level model where youth were nested within caregivers. Model 2 was a three-level model where both youth and time (wave 1 and wave 2) were nested within caregivers. Model 3 was also a three level model where both youth and time were nested within caregivers. Model 4 was a two-level model where youth were nested within caregivers. To interpret the results of the interaction effects, centred values for continuous independent variables were chosen based on inspection of histograms and descriptive information. Equations for the four models are shown in (online supplementary electronic appendix 2).

In all models, the offspring's gender, parents' age, parents' education and parents' response mode (ie, whether parents answered the self-report questionnaires in interviews face to face or answered the questionnaires by pen and paper) were entered as control variables. For some parents the response mode changed from wave 1 to wave 2. In the analyses, the response mode from $\mathrm{T} 1$ was used as adjustment variable. However, for parents only participating at T2, the response mode at T2 was used. Prior to investigating the models, unadjusted analysis with each of the independent variables was performed for comparison.

All analyses were conducted using the statistics programs $\mathrm{R}^{39}$ and SPSS, V.17. Mixed effects modelling used the $\mathrm{R}$ package nlme.

\section{RESULTS}

The results from the mixed effects analyses are shown in tables 2, 3, 4 and 5 .

Values for the adjusted model: random effects within person $\mathrm{SD}=5.64$ (95\% CI 5.20 to 6.11). Random effects within families $\mathrm{SD}=7.55$ (95\% CI 6.49 to 8.77 ). Random effects between families $\mathrm{SD}=4.69$ (95\% CI 3.19 to 8.77). 
Table 2 Model 1. Summary of mixed effect analysis for child and parent variables predicting parental emotional reactions at wave 1

\begin{tabular}{|c|c|c|c|c|c|c|}
\hline \multicolumn{7}{|c|}{ Level of parental emotional reactions, wave 1} \\
\hline \multirow[b]{2}{*}{ Variable } & \multicolumn{3}{|c|}{ Unadjusted } & \multicolumn{3}{|c|}{ Adjusted } \\
\hline & Est. & $95 \% \mathrm{Cl}$ & $\mathrm{p}$ & Est. & $95 \% \mathrm{Cl}$ & $p$ \\
\hline Youth's age & 0.13 & -0.29 to 0.54 & 0.544 & 0.19 & -0.40 to 0.77 & 0.531 \\
\hline Not living with parents & -0.03 & -2.48 to 2.43 & 0.983 & -0.74 & -3.66 to 2.19 & 0.618 \\
\hline
\end{tabular}

Youth's gender, parental age, parental education and respondent mode were controlled for in the adjusted analysis.

Male caregiver: Reference category=female caregiver.

Youth not living with parents: Reference category=living with parents.

Values for the adjusted model: Random effects within families SD $=8.99$ (95\% Cl 7.98 to 10.14). Random effects between families SD=4.82 (95\% Cl 3.15 to 7.36).

PTSS, post-traumatic stress symptoms.

Time is included in the model for the unadjusted variables.

Time difference (wave 1- Wave 2) was estimated for the following reference values: PTSS Score=26, baseline age of the youth $=18$ years, living situation $=$ not living with parents, parental gender=female caregiver.

Values for the adjusted model: Random effects within person $\mathrm{SD}=5.52$ (95\% CI 5.09 to 5.99). Random effects within families $\mathrm{SD}=7.56$ (95\% CI 6.52 to 8.77 ). Random effects between families $\mathrm{SD}=4.75$ (95\% CI 3.26 to 6.92).

Youth's symptom level was significantly related to parental emotional reactions, meaning that, the more symptoms that were reported by the youth, the higher the levels of emotional reactions in parents at both wave 1 , wave 2 and over time. At both waves and over time, mothers had significantly higher levels of emotional reactions than fathers did.

Furthermore, by not adjusting for the other variables at wave 2 , youth's age was significantly related to parental emotional reactions, indicating that the older the youth was, the higher their parents rated the level of their emotional reactions. However, this relationship was not significant when adjusting for the other variables in the model. At wave 1 and over time, there was no significant relationship between the youths' age and their parents' emotional reactions. Lastly, neither the youth's living situation at wave 1 or over time, nor change in living situation at wave 2 significantly influenced parental emotional reactions.

In model 3 (table 4), all variables had non-significant interaction effects with time ( $p>0.053)$, expect from the interaction effect with the youth's age. These interaction effects were statistically significant $(p=0.004)$, indicating that age played a different role at the different waves. See table 5 for further details about the interaction effects.

\section{DISCUSSION}

The primary aim of this study was to improve our understanding of how parents were emotionally affected following their offspring experiencing the terrorist attack at Utøya island, Norway in July 2011. Specifically, we wanted to investigate whether the level of parental reactions was associated with the symptom level, age and living situation of their offspring and whether the parent was a mother or a father. The results showed that the level

Table 3 Model 2. Summary of mixed effects analyses for child and parent variables predicting parental emotional reactions over time (wave 1 and wave 2 together), without interaction with time

Level of parental emotional reactions, wave 1 and wave 2

\begin{tabular}{lllllll}
\hline & \multicolumn{3}{c}{ Unadjusted } & \multicolumn{3}{c}{ Adjusted } \\
\hline & Est. & $95 \% \mathrm{Cl}$ & $\mathrm{p}$ & Est. & $95 \% \mathrm{Cl}$ & $\mathrm{p}$ \\
Time (W2 vs W1) & -5.82 & -6.74 to -4.97 & $<0.001$ & -5.85 & -6.74 to -4.97 & $<0.001$ \\
Youth PTSS, wave 1 & 0.20 & 0.11 to 0.29 & $<0.001$ & 0.23 & 0.13 to 0.32 & $<0.001$ \\
Youth's age & 0.35 & -0.03 to 0.73 & 0.074 & 0.26 & -0.27 to 0.79 & 0.328 \\
Youth's living with parents & 1.32 & -0.95 to 3.58 & 0.254 & 0.07 & -2.63 to 2.78 & 0.957 \\
Male caregiver & -5.06 & -6.78 to -3.34 & $<0.001$ & -5.36 & -7.18 to -3.55 & $<0.001$ \\
\hline
\end{tabular}

Youth's gender, parental age, parental education and respondent mode were controlled for in the adjusted analysis.

Male caregiver: Reference category=female caregiver.

Youth not living with parents: Reference category=living with parents.

PTSS, post-traumatic stress symptoms. 
Table 4 Model 3. Summary of interaction mixed effects analysis including interactions with time

\section{Model with interaction effects}

\begin{tabular}{|c|c|c|c|}
\hline & Est & $95 \% \mathrm{Cl}$ & $p$ \\
\hline $\begin{array}{l}\text { Time by youth post- } \\
\text { traumatic stress } \\
\text { symptoms (PTSS) }\end{array}$ & & & 0.787 \\
\hline Time by youth's age & & & 0.004 \\
\hline $\begin{array}{l}\text { Time by not living with } \\
\text { parent (s) }\end{array}$ & & & 0.553 \\
\hline Time by male caregiver & & & 0.612 \\
\hline Time & -6.66 & -7.93 to -5.39 & $<0.001$ \\
\hline Youth PTSS, wave 1 & 0.23 & 0.13 to 0.32 & $<0.001$ \\
\hline Youth PTSS, wave 2 & 0.24 & 0.13 to 0.34 & $<0.001$ \\
\hline Youth's age, wave 1 & -0.02 & -0.58 to 0.54 & 0.941 \\
\hline Youth's age, wave 2 & 0.54 & -0.02 to 1.11 & 0.060 \\
\hline $\begin{array}{l}\text { Not living with parent, } \\
\text { wave } 1\end{array}$ & -0.19 & -3.09 to 2.71 & 0.898 \\
\hline $\begin{array}{l}\text { Not living with parent, } \\
\text { wave } 2\end{array}$ & 0.51 & -2.49 to 3.50 & 0.737 \\
\hline Male caregiver, wave 1 & -5.61 & -7.58 to -3.65 & $<0.001$ \\
\hline Male caregiver, wave 2 & -5.16 & -7.23 to -3.08 & $<0.001$ \\
\hline
\end{tabular}

of parents' emotional reactions was significantly related to both youth PTSS level, and whether the parent was a mother or a father. Parents with younger offspring did not have significantly higher levels of emotional reactions than parents of older offspring.

The PERQ sum score is considered to be relatively high in the Utøya sample. It was located at the scale's 45th centile, and the PERQ mean score was almost as high as the PERQ mean score in a previous study ${ }^{21}$ consisting of parents of children in a clinical sample where all the youth scored above cut-off on PTSS (2.59 in the clinical sample vs 2.25 in the Utøya sample). This shows that parents were greatly affected by their children experiencing the Utøya terrorist attack. They felt upset, distressed, sad, guilty and concerned about what had happened to their children, and were troubled by these feelings and memories of the event while at work. During the terrorist attack, the parents found themselves in an uncertain and distressing situation. Their offspring were in a life-threatening situation, and they were unable to help. Because of the extreme nature of the event, it is not surprising that the parents experienced feelings of helplessness and strong emotional reactions. It is reasonable to assume that many parents felt that they had failed in their primary task of protecting their offspring, and many parents were probably worrying about their child's future.

It might not be surprising that parents were more emotionally distressed when their children had higher levels of PTSS. The more parents sense that their child is struggling, the more worried they may get. They might then be more pessimistic about their child's future and daily functioning. The relationship between parents' and offspring's reactions might also be explained by changes in caregiving skills and practices. For example, worries and lack of sleep might influence a parent's ability to be emotionally present for their offspring. Furthermore, feeling guilty may make parents overprotective or cause them to overcompensate because they feel sorry for their child. This may contribute to preserving the youth's sense of threat or feelings that life will never be the same. These are maladaptive cognitions that have been found to maintain PTSS both in youth and adults. ${ }^{40}$ Over time, these altered parenting practices may again influence the children, providing a potential explanation for the

Table 5 Model 4. Summary of mixed effect analysis for child and parent variables predicting parental emotional reactions at wave 2

\section{Level of parental emotional reactions, wave 2}

\begin{tabular}{|c|c|c|c|c|c|c|}
\hline \multirow[b]{2}{*}{ Variable } & \multicolumn{3}{|c|}{ Unadjusted } & \multicolumn{3}{|c|}{ Adjusted } \\
\hline & Est. & $95 \% \mathrm{Cl}$ & $\mathrm{p}$ & Est. & $95 \% \mathrm{Cl}$ & $\mathrm{p}$ \\
\hline Youth PTSS, wave 2 & 0.20 & 0.07 to 0.33 & 0.003 & 0.26 & 0.12 to 0.39 & $<0.001$ \\
\hline Youth's age & 0.75 & 0.26 to 1.25 & 0.003 & 0.32 & -0.41 to 1.05 & 0.389 \\
\hline Change in living situation, W1 to W2 & & & 0.200 & & & 0.937 \\
\hline 1. Moving out versus no change, living at home & -0.68 & -4.85 to 3.49 & 0.746 & -0.88 & -4.98 to 3.23 & 0.672 \\
\hline $\begin{array}{l}\text { 2. No change, living away from home versus no } \\
\text { change, living at home }\end{array}$ & 3.14 & -0.05 to 6.33 & 0.054 & 0.43 & -3.63 to 4.50 & 0.833 \\
\hline 3. Moving home versus no change, living at home & 0.85 & -7.05 to 8.75 & 0.832 & 0.0 .96 & -6.64 to 8.57 & 0.803 \\
\hline Male caregiver & -4.67 & -7.08 to -2.26 & $<0.001$ & -5.33 & -7.91 to -2.74 & $<0.001$ \\
\hline
\end{tabular}

Youth's gender, parental age, parental education and respondent mode are controlled for in the adjusted analysis.

Male caregiver: Reference category=female caregiver.

Change in living situation wave 1 to wave 2: Reference category=no change, living at home.

Values for the adjusted model: Random effects within families SD=9.70 (95\% Cl 8.46 to 11.12). Random effects between families SD $=4.40$ (2.38 to 8.15).

PTSS, post-traumatic stress symptoms. 
relationship between the youth's symptoms and parental emotional reactions.

The youth in the current study ranged in age from 13 years to 32 years old. The youngest might be seen as the most vulnerable, with less coping skills to handle difficult situations, thus having the most worried parents. However, the results from this study are consistent with parenting having no age limit. Parents, whose children were young adults, had moved away from home and lived lives of their own might have been just as worried as parents of younger youth. In fact, at wave 2, it seemed that parents of older youth became more concerned as time went by, but this relationship was not statistically significant after adjusting for the other variables in the model. The finding that the age of the youth was not significantly associated with parental reactions is in line with some studies investigating parents of seriously ill or injured children. ${ }^{26} 2842$ However, the sample in these studies consisted of children much younger than the youth in the Utøya sample, making the studies less comparable. Few other studies have looked at the reactions of parents of young adults who are traumatised. Parents might be in a good position to protect their offspring while they are young, and they might feel more in control as they can monitor their youth's development. As their children become more independent and establish their own lives, parents may feel that they are no longer able to protect and look after them. Between the ages of 18 years and 19 years, the majority of Norwegian youth are in a transition between high school, studies and careers, and some youth are also creating their own families. Even after losing daily contact with their children, parents may continue to have elevated levels of emotional reactions. When, in addition, their offspring have experienced a life-threatening situation, it might be even more challenging for parents to let them transition independently into adulthood.

At both time points, the results showed that the female caregivers were more worried, distressed and sad, and felt more guilt than the male caregivers did. Previous literature has found that women report higher levels of mental health symptoms such as PTSD, depression and anxiety than men do. ${ }^{24}{ }^{25}$ In light of these studies, it is reasonable to assume that mothers are more likely to develop a broader spectrum of emotional reactions related to their child's trauma than fathers are. More intense involvement in the family and their children's lives might be another explanation for why mothers express more worries and emotional reactions than fathers do. We had expected that gender equality regarding child-rearing would leave fathers feeling just as emotionally upset as mothers. However, it might be that despite efforts to involve men in child-rearing, mothers still feel that they are expected to be the primary caregiver, hence feeling more upset when their children experience something terrible and do not recover well. One study has investigated whether there is a gender difference between parents in the support they give to their child following sexual abuse. This study found that the caregiver's gender was related to the non-specific support they gave to the child who had experienced abuse. ${ }^{43}$ Mothers provided their children with instrumental support, emotional support and support in the outside world more often than fathers did. The authors believe that this could reflect the frequency with which mothers accompany children in their daily routines and tasks, an explanation that might be applicable to the findings in the current study. If mothers are involved more directly in their offspring's daily lives, they might also speak with them more often. Consequently, they might have a better understanding of their offspring's feelings, and thus become more concerned when their children fail to improve. Another possible explanation for the higher levels of reactions in mothers might be that it is more socially acceptable for female caregivers to express worries and emotional reactions. In fact, they may even feel that there is a societal expectation to express emotions. It would be of future interest to investigate this assumption further.

\section{Limitations and future directions}

Although this study provides us with a greater understanding of parents' emotional reactions to their children experiencing traumatising events, certain limitations must be taken into account when interpreting the findings. First, although the same PERQ questions were applied, most parents of youth $\geq 19$ years answered a paper-and-pencil questionnaire mailed to their homes, whereas most parents of the survivors $\leq 18$ years had the opportunity to ask the interviewer questions during the self-report. Social desirability may thus have impacted the results. ${ }^{44}$

Second, there could be a selection bias because not all parents of youth who experienced the Utøya island attack participated in the study. Therefore, we cannot conclude that the results apply to the non-participating parents, and we should be careful with generalising the findings. A third limitation is the missing data. In the second wave in particular, the variable of change in living situation contained a substantial amount of missing data, as we required completed scores at both the first and the second measurement points for this variable. This limited all analyses conducted at wave 2 . However, despite these limitations, the findings may bring us one step closer to understanding parents' reactions to their children's traumatic experiences.

It is necessary to understand parents' emotional reactions to their children's trauma in order to provide appropriate help to both parents and children. Emotional reactions from loving and protective parents are to be expected. At the same time, excessive worrying and disproportionate emotional reactions may reduce parents' ability to handle, care for and support their children. Parental stress may pass to the child, and disrupt their need for autonomy and independence. Helping parents to find a balance between caring and overreacting may assist families in their struggle to heal from trauma. 
Acknowledgements The authors thank all the youth and their parents for their participation in the study. The authors also thank all the health professionals who participated in the interviewing and data collection procedure.

Contributors GD and TJ developed the study design. TH, GD and TJ participated in collecting the data. TH and TW-L conducted the analyses. All authors were involved in interpreting the results. TH and TJ produced the first draft of the manuscript. All authors participated with critical comments on further drafts. All authors read and approved the final version of the manuscript.

Funding This work was funded by the Norwegian Research Council and the Norwegian Directorate of Health.

Competing interests None declared.

Patient consent Detail has been removed from this case description/these case descriptions to ensure anonymity. The editors and reviewers have seen the detailed information available and are satisfied that the information backs up the case the authors are making.

Ethics approval The study was approved by the Regional Committees for Medical and Health Research Ethics in Norway.

Provenance and peer review Not commissioned; externally peer reviewed.

Data sharing statement Due to the fact that the research project is still ongoing and that the consents restrict data sharing outside the originally designed research project, there is no data that can be shared at the present moment. However requests for collaboration and questions regarding the data can be addressed to the leader of the project, Grete Dyb (grete.dyb@nkvts.no).

Open Access This is an Open Access article distributed in accordance with the Creative Commons Attribution Non Commercial (CC BY-NC 4.0) license, which permits others to distribute, remix, adapt, build upon this work non-commercially, and license their derivative works on different terms, provided the original work is properly cited and the use is non-commercial. See: http://creativecommons.org/ licenses/by-nc/4.0/

(c) Article author(s) (or their employer(s) unless otherwise stated in the text of the article) 2017. All rights reserved. No commercial use is permitted unless otherwise expressly granted.

\section{REFERENCES}

1. Davies MG. Parental distress and ability to cope following disclosure of extra-familial sexual abuse. Child Abuse Negl 1995;19:399-408.

2. Slaven-Lee PW, Padden D, Andrews CM, et al. Emotional distress and health risk behaviours of mothers of United States Marines. Int Nurs Rev 2011;58:164-70.

3. Famularo R, Fenton T, Kinscherff R, et al. Maternal and child posttraumatic stress disorder in cases of child maltreatment. Child Abuse Negl 1994;18:27-36.

4. Dyb G, Holen A, Steinberg AM, et al. Alleged sexual abuse at a day care center: impact on parents. Child Abuse Negl 2003;27:939-50.

5. Woolf C, Muscara F, Anderson VA, et al. Early Traumatic Stress Responses in Parents Following a Serious Illness in Their Child: a systematic review. J Clin Psychol Med Settings 2016;23:53-66.

6. Scrimin S, Axia G, Capello F, et al. Posttraumatic reactions among injured children and their caregivers 3 months after the terrorist attack in Beslan. Psychiatry Res 2006;141:333-6.

7. Elliott AN, Carnes CN. Reactions of nonoffending parents to the sexual abuse of their child: a review of the literature. Child Maltreat 2001;6:314-31.

8. Lewin L, Bergin C. Attachment behaviors, depression, and anxiety in nonoffending mothers of child sexual abuse victims. Child Maltreat 2001;6:365-75.

9. Muscara F, McCarthy MC, Woolf C, et al. Early psychological reactions in parents of children with a life threatening illness within a pediatric hospital setting. Eur Psychiatry 2015;30:555-61.

10. Cummings EM, Davies PT, Campbell SB. Developmental psychopathology and family process. New York: The Guilford Press, 2000.

11. Scheering MS, Zeanah $\mathrm{CH}$. A relational perspective on PTSD in early childhood. J Trauma Stress 2001;14:799-815.

12. Cohen E. Parenting in the throes of traumatic events: Relational risks and protection processes. In: Ford J, Pat-Horenczyk R, Brom $\mathrm{D}$, eds. Treating traumatized children: Risk, resilience and recovery. Florence, KY: Routledge, 2009:72-84.
13. Trickey D, Siddaway AP, Meiser-Stedman R, et al. A meta-analysis of risk factors for post-traumatic stress disorder in children and adolescents. Clin Psychol Rev 2012;32:122-38.

14. Cohen JA, Deblinger E, Mannarino AP, et al. A multisite, randomized controlled trial for children with sexual abuse-related PTSD symptoms. J Am Acad Child Adolesc Psychiatry 2004:43:393-402.

15. Deblinger E, Mannarino AP, Cohen JA, et al. A follow-up study of a multisite, randomized, controlled trial for children with sexual abuse-related PTSD symptoms. J Am Acad Child Adolesc Psychiatry 2006;45:1474-84.

16. Holt T, Cohen J, Mannarino A, et al. Parental Emotional Response to Children's Traumas. J Aggress Maltreat Trauma 2014;23:1057-71.

17. Foster K, Young A, Mitchell R, et al. Experiences and needs of parents of critically injured children during the acute hospital phase: A qualitative investigation. Injury 2017;48:114-20.

18. Shudy M, de Almeida ML, Ly S, et al. Impact of pediatric critical illness and injury on families: a systematic literature review. Pediatrics 2006;118:S203-S218.

19. Mannarino AP, Cohen JA. Family-related variables and psychological symptom formation in sexually abused girls. J Child Sex Abus 1996;5:105-20.

20. Thoresen S, Jensen TK, Wentzel-Larsen T, et al. Parents of terror victims. A longitudinal study of parental mental health following the 2011 terrorist attack on Utøya Island. J Anxiety Disord 2016;38:47-54

21. Holt T, Jensen TK, Wentzel-Larsen T. The change and the mediating role of parental emotional reactions and depression in the treatment of traumatized youth: results from a randomized controlled study. Child Adolesc Psychiatry Ment Health 2014;8:11.

22. Pynoos RS, Steinberg AM, Piacentini JC. A developmental psychopathology model of childhood traumatic stress and intersection with anxiety disorders. Biol Psychiatry 1999;46:1542-54.

23. Bowlby J. Attachment and loss: Loss, sadness and depression. New York, NY: Basic Books, 1980.

24. Brewin CR, Andrews B, Valentine JD. Meta-analysis of risk factors for posttraumatic stress disorder in trauma-exposed adults. $J$ Consult Clin Psychol 2000;68:748-66.

25. Nooner KB, Linares LO, Batinjane J, et al. Factors related to posttraumatic stress disorder in adolescence. Trauma Violence Abuse 2012;13:153-66.

26. Landolt MA, Ystrom E, Sennhauser FH, et al. The mutual prospective influence of child and parental post-traumatic stress symptoms in pediatric patients. J Child Psychol Psychiatry 2012;53:767-74.

27. McCarthy MC, Ashley DM, Lee KJ, et al. Predictors of acute and posttraumatic stress symptoms in parents following their child's cancer diagnosis. J Trauma Stress 2012;25:558-66.

28. Balluffi A, Kassam-Adams N, Kazak A, et al. Traumatic stress in parents of children admitted to the pediatric intensive care unit. Pediatr Crit Care Med 2004;5:547-53.

29. Kassam-Adams N, Fleisher CL, Winston FK. Acute stress disorder and posttraumatic stress disorder in parents of injured children. J Trauma Stress 2009;22:294-302.

30. Pleck J. Paternal involvement: Revised conceptualization and theoretical linkages with child outcomes. Lamb ME, ed. The role of the father in child development. 5th ed. Hoboken, New Jersey: Wiley, 2010:58-93.

31. Leira A. Parenthood change and policy reform in Scandinavia 1970s-2000s. In: Ellingsæter AL, Leira A, eds. Politicising Parenthood in Scandinavia Gender relations in welfare states. Bristol: Policy Press, 2006:27-51.

32. Kjeldstad R, Lyngstad JUtradisjonell likestilling? Analyser av undersøkelsen Livsløp, generasjon og kjønn (LOGG) Untraditional gender equality?. Statistics Norway 2010.

33. Dyb G, Jensen TK, Nygaard E, et al. Post-traumatic stress reactions in survivors of the 2011 massacre on Utøya Island, Norway. Br J Psychiatry 2014;204:361-7.

34. Stene LE, Dyb G. Research participation after terrorism: an open cohort study of survivors and parents after the 2011 Utøya attack in Norway. BMC Res Notes 2016;9:57.

35. Holt T, Cohen JA, Mannarino A. Factor structure of the parent emotional reaction questionnaire: analysis and validation. Eur J Psychotraumatol 2015;6:28733.

36. Steinberg AM, Brymer MJ, Decker KB, et al. The University of California at los angeles post-traumatic stress disorder reaction index. Curr Psychiatry Rep 2004;6:96-100.

37. DSM-IV, American Psychiatric Association. Diagnostic and statistical manual of mental disorders DSM IV- APA. 4th edition, 1994.

38. Pinheiro J, Bates D. Mixed effects models in S and S-Plus. New York: Springer-Verlag, 2000. 
39. Hornik K. The (20) \{FAQ\}. (3-900051-08-9). 2012 http://CRAN.Rproject.org/doc/FAQ/R-FAQ.html

40. Meiser-Stedman R, Dalgleish T, Glucksman E, et al. Maladaptive cognitive appraisals mediate the evolution of posttraumatic stress reactions: A 6-month follow-up of child and adolescent assault and motor vehicle accident survivors. J Abnorm Psychol 2009;118:778-87.

41. Ehlers A, Clark DM. A cognitive model of posttraumatic stress disorder. Behav Res Ther 2000;38:319-45.
42. Winston FK, Kassam-Adams N, Vivarelli-O'Neill C, et al. Acute stress disorder symptoms in children and their parents after pediatric traffic injury. Pediatrics 2002;109:e90.

43. Cyr M, Hébert M, Frappier J-Y, et al. Parental Support Provided by Nonoffending Caregivers to Sexually Abused Children: a comparison between mothers and fathers. J Child Custody 2014;11:216-36.

44. PedhazurEJ, SchmelkinLP. Measurement, Design, and Analysis: An Integrated Approach. Hillsdale, New Jersey: Lawrence Erbaum Associates, 1991. 